pterygoid shows two kinds of dentition; on its outer edge is a single row of twenty-six large teeth of equal size, which are somewhat smaller than those of the maxillary bone. Internal to these on the anterior part of the pterygoid are from three to six irregular rows of short pointed teeth similar to those on the parasphenoid. In the under-jaw there are thirty teeth.

This instalment of Dr. Fritsch's work leads us to look forward to its subsequent progress with great interest. It is a monument of conscientious labour and admirable skill in deciphering remains in which the characters presented more than ordinary difficulty.

H. G. Seeley.

\title{
CORRESPONDENTCE.
}

THE PURPLE BOCLDER-CLAY AT HOLDERNESS.

SIr,-In the excellent account of English glacial deposits, given in the second edition of "The Great Ice Age," it is stated that " in Holderness the purple clay is quite unstratified." It is true, that in many places the "Purple Boulder-clay" is unstratified; but in many others it is distinctly stratified. The stratified and unstratified portions are, however, so mixed up together, and run so into one another, as to be quite inseparable. The deposit has also been much shoved about, the thrust having in some well-marked cases come from the N.N.E.

Driffield, Oct. $9 t h, 1879$. J. R. Dakyns.

ON THE CLASSIFICATION OF THE BRITISH PRE-CAMBRIAN ROCKS.

SIR,-Will you kindly call attention to the fact that by some mistake the word not has been left out after the word did in my paper, p. 434, line 19 from bottom of page. The sentence should read, "If these movements also did not take place, etc." As the absence of this one little word does away with the proper meaning, I shall feel obliged if you will kindly notice it in the next Number of the GEol. Mag.

Hendon, N.W., Oct. 3, 1879.

Hy. Hicks.

\section{SURFACE GEOLOGY OF THE MISSISSIPPI VALLEY.}

Mr. W. J. Mc Gee writes from Farley, Iowa, September 18, 1879, in reference to his communication, which appeared in the GroL. Magazine for August, pp. 353-362, and September, pp. 412-421:"Thanks for your care in revising proofs of my paper in the GeoL. Miag. A very few errors have crept in, however, which I will note.

\section{W. J. Mc GEE."}

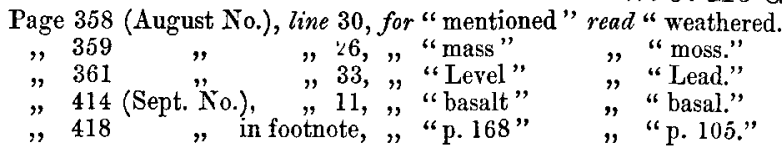

\section{COLUMNAR SANDSTONE IN SAXON SWITZERLAND.}

We are requested by $\mathrm{Mr}$. Walter Keeping to make the following corrections in his article which escaped notice-namely, at p. 438, line 2 from foot, for 'binding' read 'bending.' and on p. 441, line 8 from top, for 'Yorkshire,' read 'Derbyshire.'Edit. Geol. Mag. 